\title{
Effects of adult sex ratio on larvae number and survival of fry in Xiphophorus maculatus (Cyprinodontiformes: Poeciliidae)
}

\author{
Farshid Davoodi and Abbas Raisi* \\ Department of Clinical Sciences, Faculty of Veterinary Medicine, Lorestan University, 6815144316 \\ Khorramabad, Iran \\ Corresponding author ${ }^{\boxplus}$ : raisi.a@lu.ac.ir
}

Received: 14 October 2019

Accepted: 30 December 2019

Published online: 31 December 2019

\begin{abstract}
In this study, differing adult sex ratios of the Southern platyfish, Xiphophorus maculatus were examined for fish larval number and the survival of fish fry. Sixty adult individuals of $X$. maculatus were randomly divided into 5 equal groups with various male to female sex ratios of 1:1, 1:2, 1:3, 2:1, and 3:1, respectively. After a month when the male and female fish were kept together in different experimental groups, all the female fish became pregnant. Four different factors in each group were recorded - notably the length of pregnancy, number of fry produced, number of live fry after 40 days, and final percentage survival. According to the analyzed data, the number of fry, the number of surviving fry after 40 days, and the percentage survival were significantly higher in the first group with a male to female sex ratio of 1:1 than the other experimental groups. Our results suggest that the best sex ratio for maximum efficiency is $1: 1$.
\end{abstract}

Key words: Southern platyfish, sex ratio, fish fry, reproduction

\section{Introduction}

Fish of the genus Xiphophorus Heckel, with 28 recognized species (Nelson et al., 2016), are found on the Atlantic slope of Mexico and adjacent parts of Central America. The southern platyfish, Xiphophorus maculatus (Günther) is an ovoviviparous and non-aggressive small fish with varied coloring that is easy to reproduce and maintain (Prodocimo and Freire, 2001). Xiphophorus maculatus inhabit slow-flowing lotic systems and develop well in artificial environments (Page and Burr, 1991). The size of adult specimens of X. maculatus differ from 14 to $45 \mathrm{~mm}$ (Kallman, 1983).

Regarding sexual dimorphism, immature fish of both sexes look the same, but when they mature, the anal fin of the male is transformed into a bony structure, the gonopodium (Fig. 1), which plays a vital role during sperm transfer. Brood intervals are temperature dependent, and if $X$. maculatus is maintained at an average temperature of $23{ }^{\circ} \mathrm{C}$, most broods are born at intervals between 31-39 days (Kallman, 1975). Different parameters can affect sexual maturation and the overall reproductive health of the fish including: water temperature, nutrition, light, genetic features, age, size, and social conditions, such as stress and the presence of the opposite sex. There is a lot of desire for mating in male X. maculatus and the females are always under pressure to mate by the male gender (Houde, 1997). 


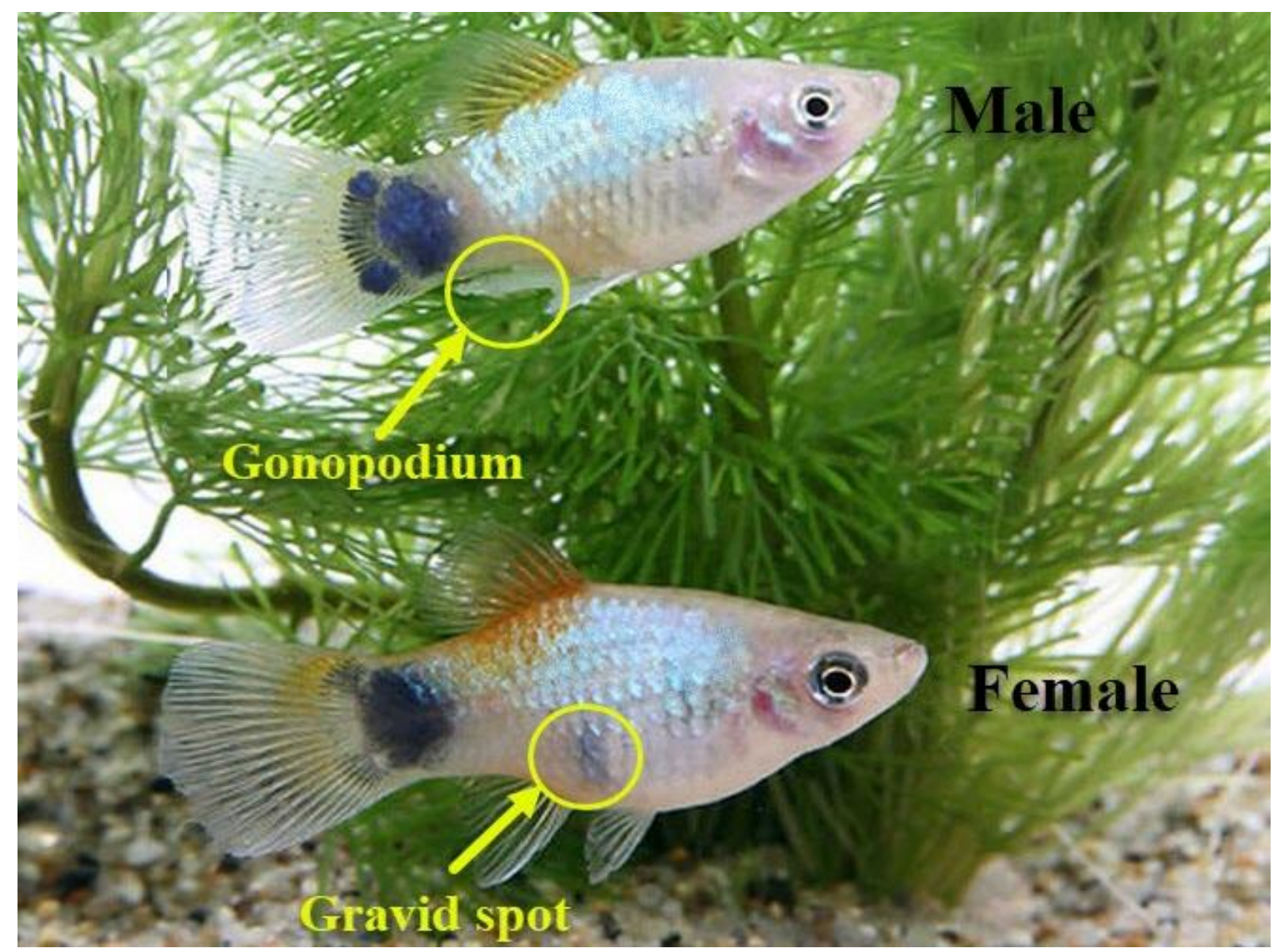

Figure 1: Sexual dimorphism in Xiphophorus maculatus. The yellow arrows show the gonopodium in males and the gravid spot in females.

Aquarium keeping is one of the most popular hobbies with millions of enthusiasts worldwide (Livengood and Chapman, 2007). Combined the countries of the European Union are the largest market for ornamental fishes; however, the United States of America is the single largest importer of ornamental fish species in the world (Fernando and Phang, 1985). There are many breeding centers of ornamental fish species all over the world, for instance, Singapore is well known as a breeding center for the Guppy, Poecilia reticulata Peters, another member of the livebearing family Poeciliidae, with $X$. maculatus.

Iran has been recognized as one of the major freshwater fish biodiversity hotspots in the Middle East with 297 species, among them 173 species are native and 95 species endemic (Esmaeili et al., 2018). As in other parts of the world, the number of exotic fish known in Iran has been growing in recent decades, and 29 exotic species have been confirmed and recorded, accounting for about $9.76 \%$ of all freshwater fish known in the country (Esmaeili et al., 2018). Among them, 8 exotic ornamental fish species have been introduced to Iranian inland water basins due to the aquarium trade (Mousavi-Sabet, 2019). Fortunately, X. maculatus has not been reported in Iranian inland waters despite the vigorous aquarium trade.

Different breeding centers use different male to female sex ratios for X. maculatus, for example, in Singapore a sex ratio of 1:3 and 1:4 have been used and even as high as 1:10. A 1:3 male to female sex ratio has been suggested and recommended in a previous study (Fernando and Phang, 1985). There are many published papers about sex ratios in the fry of livebearers (in Iran for instance - Mousavi-Sabet et al., 2012; Faghani-Langroudi et al., 2014) but there is no published research about the adult sex ratio in X. maculatus. In this study, we 
examine the effects of adult sex ratios on numbers and survival of fry of $X$. maculatus to help breeding centers to increase their production efficiency.

\section{Material and Methods}

Seventeen aquariums with 20 liter capacity (40 cm length, $20 \mathrm{~cm}$ width, and $30 \mathrm{~cm}$ height) were prepared (15 aquariums for the investigation and 2 aquariums for the quarantine of sick fish). A Hailea AC Air Compressor (102W) was utilized for aeration. A filter was installed in each tank for filtering and cleaning the water, and a heater was placed in each tank to stabilize the temperature at $26.2 \pm 0.61{ }^{\circ} \mathrm{C}$. One drop per liter of Tetra Aqua Safe start drop (Tetra, Hanover, Germany) was added to each aquarium to dechlorinate and condition the water. Each aquarium sat for 48 hours before fish were added.

Thirty male and 30 female individuals of $X$. maculatus were bought from the Mahalat breeding center, Mahalat, Iran, and it was emphasized that female fish should not be pregnant. At first, the fish were placed in quarantine tanks to detect sick fish. Then females and males were maintained separately for a month to ensure that there were no pregnant fish. Eventually, 5 pregnant females were found, and were removed from the experiment. The fish were fed fish meal (Tetra Temperate Flakes, Tetra, Germany) and nauplii of Artemia in the morning and evening. To prevent contamination of the aquarium water, one-third of the water in each aquarium was siphoned and replaced with fresh conditioned water once a week.

Fish were then divided into 5 groups with different male to female sex ratios of 1:1, 1:2, 1:3, 2:1, 3:1 (MF, M2F, M3F, 2MF and 3MF respectively) and were put in each tank (26.2 \pm 0.61 ${ }^{\circ} \mathrm{C}$, pH $7.45 \pm 0.07$, total ammonia levels of $0.081 \mathrm{mg} \mathrm{L}^{-1}$, dissolved oxygen levels: $8.69 \pm$ $0.21 \mathrm{mg} \mathrm{L}^{-1}$, total hardness level: $24 \pm 2 \mathrm{mg} \mathrm{L}^{-1} \mathrm{CaCO} 3$, alkalinity level: $41 \pm 1 \mathrm{mg} \mathrm{L}^{-1}$ CaCO3, conductivity: $0.041 \mathrm{~S} \mathrm{~cm}^{-1}$ ).

After approximately one month all females were pregnant, based on the appearance of a black gravid spot near the anal fin (Fig. 1), and size of the abdomen. Pregnant females were transferred to tanks intended for giving birth. The parturition period for each group was recorded. Offspring in each group (Fig. 2) were counted, and after 40 days the percentage of surviving fry were calculated.

\section{Statistical analysis}

The one-sample Kolmogorov-Smirnov test was applied to analyze distributions of the experimental groups. According to the Kolmogorov-Smirnov test results, all data had a normal distribution and were reported as mean \pm standard deviation. Analysis of variance was performed in groups and since $\mathrm{F}$ was significant, comparisons of means between groups were performed relying on a one-way ANOVA with Scheffe's test post hoc. Analyses were carried out by a standard commercial statistical package IBM SPSS Statistics V25.

\section{Results}

The mean of all values, and standard deviations are presented in Table 1.

\section{Parturition Period}

The parturition or prenatal period significantly increased, when the number of females increased, but the number of males remained constant $(p<0.05)$ (Table 1). Also, it significantly reduced when the number of males increased, but the female count is constant $(p<0.05)$. 


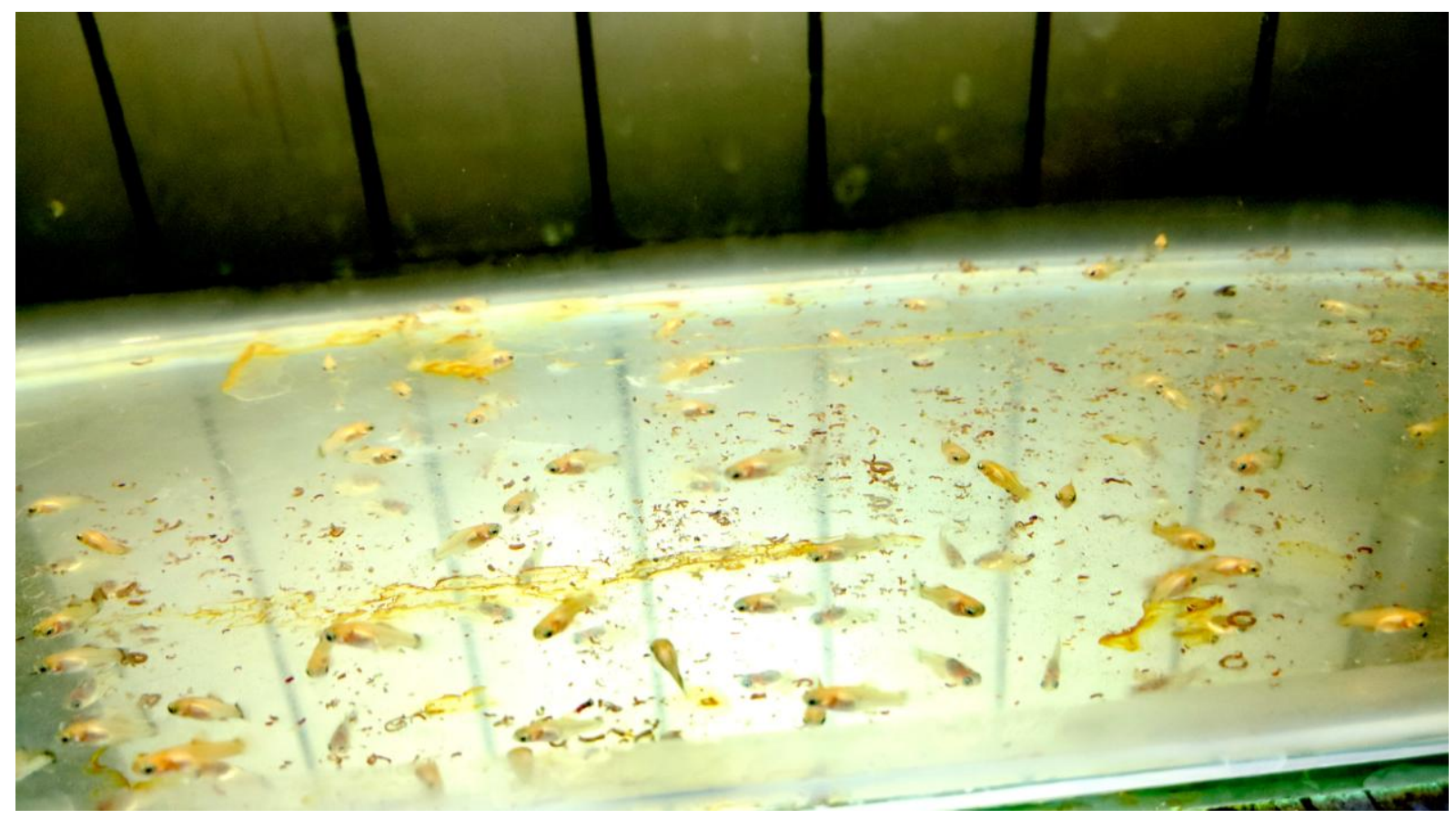

Figure 2: The fry of Xiphophorus maculatus after birth in captivity.

Table 1: Comparison of pairwise means in different groups.

\begin{tabular}{ccccc}
\hline \multirow{2}{*}{ Groups } & \multicolumn{4}{c}{ Means } \\
\cline { 2 - 5 } & $\begin{array}{c}\text { Time until } \\
\text { birth (days) }\end{array}$ & $\begin{array}{c}\text { Number of } \\
\text { fry }\end{array}$ & $\begin{array}{c}\text { Number of live fry } \\
\text { after 40 days }\end{array}$ & $\begin{array}{c}\text { Percentage } \\
\text { Survival (\%) }\end{array}$ \\
\hline MF & $30.66 \pm 1.15^{\mathrm{bc}}$ & $42.33 \pm 2.51^{\mathrm{a}}$ & $39.00 \pm 1.00^{\mathrm{a}}$ & $92.13 \pm 3.10^{\mathrm{a}}$ \\
\hline M2F & $35.33 \pm 1.52^{\mathrm{b}}$ & $33.00 \pm 3.00^{\mathrm{b}}$ & $25.33 \pm 3.51^{\mathrm{b}}$ & $76.75 \pm 8.92^{\mathrm{ab}}$ \\
M3F & $39.33 \pm 2.08^{\mathrm{a}}$ & $27.00 \pm 2.00^{\mathrm{bc}}$ & $20.00 \pm 0.00^{\mathrm{bc}}$ & $74.07 \pm 4.65^{\mathrm{b}}$ \\
\hline 2MF & $27.33 \pm 1.52^{\mathrm{cd}}$ & $19.00 \pm 1.00^{\mathrm{d}}$ & $17.66 \pm 1.15^{\mathrm{c}}$ & $92.94 \pm 3.07^{\mathrm{a}}$ \\
\hline MMF & $24.00 \pm 1.00^{\mathrm{d}}$ & $22.00 \pm 2.00^{\text {cd }}$ & $19.66 \pm 0.57^{\mathrm{c}}$ & $89.36 \pm 5.92^{\mathrm{ab}}$ \\
\hline
\end{tabular}

"Means followed by the similar letters in each column do not differ significantly by the Scheffe's test $(p<0.05)$.

\section{Number of fry}

There is a significant difference between the M2F and M3F groups when compared to the MF group ( $p<0.05)$ and consequently as the number of females to males increased, the number of offspring decreased significantly $(p<0.05)$. The difference between the $2 \mathrm{MF}$ and $3 \mathrm{MF}$ groups compared to the MF group is significant $(p<0.05)$, indicating that increasing the male to female sex ratio increment led to a reduced larvae number (Table 1).

\section{Number of live fry after 40 days}

The number of live larvae after 40 days is remarkably higher in the MF group than M3F and M2F groups $(p<0.05)$, showing that increasing the number of females resulted in a decrease in live larvae after 40 days (Table 1). The significant difference of the MF group with $2 \mathrm{MF}$ and $3 \mathrm{MF}$ groups reveals that increasing the number of male fish reduced larvae viability after 40 days $(p<0.05)$. 


\section{Percentage survival}

There were significant differences between the MF and the M3F groups and between the $2 \mathrm{MF}$ and the $\mathrm{M} 3 \mathrm{~F}$ groups $(p<0.05)$. In the $3 \mathrm{MF}$ group an increase in the percentage of surviving fry is seen when compared to the M2F and the $3 \mathrm{MF}$ groups, but it was not significant $(p>0.05)$ (Table 1).

\section{Discussion}

Ornamental fish markets are a huge industry that creates many jobs and helps to increase exports to foreign countries. Ornamental fish keeping is a popular hobby and is developing very fast. Therefore, breeders need to be able to grow ornamental fish with high efficiency ( $\mathrm{Ng}, 2016)$.

Internal and external factors influence reproduction in fish. One of the well-known internal factors is the endocrine system that controls gametogenesis (i.e. spermatogenesis and oogenesis) in both sexes. External factors involved in fish reproduction include: temperature, stress, nutrition, photo period, and other environmental factors (Pankhurst, 1997; Harlıoğlu and Farhadi, 2017). The nervous and hormonal systems control the reproductive cycle in fish, by receiving messages from sensory organs such as the eyes and skin and the nerves deliver them to the brain. The brain analyzes these sensory messages and sends a message to the pituitary, and the pituitary gland secretes hormones that set gonadal function. This is called the brain-pituitary-gonadal axis (Zanuy et al., 2001).

Previous studies on the Guppy and Convict cichlid, Amatitlania nigrofasciata (Günther) have shown that the number of fry decreased with increasing female to male sex ratio (Changizi et al., 2008; Shafiee et al., 2013). In the present study when the number of females to males increased, the number of fry were reduced and these results are consistent with previous studies. In the same experiments on the Convict cichlid, it was demonstrated that increasing the female to male ratio reduces the hatching of eggs (Changizi et al., 2008).

We were able to demonstrate that when the female to male sex ratio of $X$. maculatus increased the length of the fertility period increased. These results match those observed in earlier studies (Changizi et al., 2008; Ghiasvand et al., 2009; Shafiee et al., 2013). Increased female counts decreased fry survival rate after 40 days, and similar results from Poecilia latipinna (Lesueur) and Poecilia reticulata also indicated a reduction in the percentage of surviving fry (Ghiasvand et al., 2009; Shafiee et al., 2013). In this study, the number of hatched fry decreased with the increasing number of male fish, which is in agreement with previous results in Poecilia reticulata and Poecilia latipinna, but in A. nigrofasciata the number of eggs and larvae increased with the increase in male to female ratio (Changizi et al., 2008). One possible reason is that due to external fertilization in A. nigrofasciata, the increase in the number of male fish, increased the chance of spermatozoal fertilization with oocytes and led to an increase in the number of larvae.

Considering the above results, it can be seen that by increasing the number of females versus males possibly leads to decreased mating and also increased estrogenic hormones produced by the females. This may cause increased pressure on the sex hormones and gonads of the male fish, resulting in reduced androgens and reduced spermatogenesis; ultimately leading to decreased sperm production more defective sperm. These factors may lead to increased time elapsed until birth, and a decrease in the number of fry. Also, a decrease in yolk stimulating hormones have negative effects, and yolk production is often not sufficiently performed, but with the increase in the number of males versus females the induction of ovulation by pheromones produced by males is more complete. As a result yolk production is more 
extensive, but the high volume of effective male steroids in the environment creates a negative feedback, and the production of sperm that is effective in fertilization is diminished, resulting in lower numbers of fry but with a larger yolk sac and higher survival rates. On the other hand, if males are increased more than females, then females have a reduced feeding efficiency resulting in reduced numbers of fry.

The results show that increasing the proportion of female fish to male fish decreased the number of fry and their survival rates. On the other hand, with the increase in the number of male fish in the environment, the risk of sexual harm to female fish could be increased and could lead to immune and reproductive disturbances. It can be concluded that the best sex ratio with the highest concordance and the highest survival rate of fry is the sex ratio of one male to one female (MF). It would be interesting to assess the effects of adult sex ratio on larval sex ratio in future studies.

\section{Acknowledgements}

We thank the anonymous reviewers for their careful reading of our manuscript and their valuable comments and suggestions.

\section{References}

Changizi, R., Matinfar, A., Jamili, S. and Ghiasvand, Z. (2008). Comparing the breeding indices in different sex ratio and photoperiod in Cichlosoma nigrofasciatum as an ornamental fish. Pajouhesh-va-Sazandegi, 21 (2): 135-143. [in Persian]

Esmaeili, H. R., Sayyadzadeh, G., Eagderi, S. and Abbasi, K. (2018). Checklist of freshwater fishes of Iran. FishTaxa, 3 (3): 1-95.

Faghani-Langroudi, H., Esmailpour-Chokami, H., Rohani-Rad, M. and Mousavi-Sabet, H. (2014). Sex reversal, mortality rate and growth performance of platy Xiphophorus variatus (Poeciliidae) treated by methyltestosterone. Poeciliid Research, 4 (1): 6-12.

Fernando, A. and Phang, V. P. E. (1985). Culture of the guppy, Poecilia reticulata, in Singapore. Aquaculture, 51 (1): 49-63. https://doi.org/10.1016/0044-8486(85)90239-X

Ghiasvand, Z., Matinfar, A. and Jamili, S. (2009). Survey on photoperiodic and sexual ratio effects on reproduction of Poecilia latipinna. Pajouhesh-va-Sazandegi, 21 (4): 16-24. [in Persian]

Harlıoğlu, M. M. and Farhadi, A. (2017). Factors affecting the reproductive efficiency in crayfish: implications for aquaculture. Aquaculture Research, 48 (5): 1983-1997. https://doi.org/10.1111/are.13263

Houde, A. E. (1997). Sex, color, and mate choice in guppies: Princeton University Press. 224 pp.

Kallman, K. D. (1975). The platyfish, Xiphophorus maculatus, In: King, R. C. (Eds.), Handbook of Genetics. Handbook of Genetics. Springer, Boston, MA. pp. 81-132.

Kallman, K. D. (1983). The sex determining mechanism of the poeciliid fish, Xiphophorus montezumae, and the genetic control of the sexual maturation process and adult size. Copeia, 1983 (3): 755-769. https://doi.org/10.2307/1444343

Livengood, E. and Chapman, F. A. (2007). The ornamental fish trade: An introduction with perspectives for responsible aquarium fish ownership. University of florida IFAS Extension, 1-8. 
Mousavi-Sabet, H. (2019). Exotic ornamental fishes in Iranian inland water basins: an updated checklist. Journal of Animal Diversity, 1 (1): 1-10. https://doi.org/10.29252/JAD.2019.1.1.1

Mousavi-Sabet, H., Langroudi, H. F. and RohaniRad, M. (2012). Sex reversal, mortality rate and growth of guppy (Poecilia reticulata) affected by 17-alpha methyltestosterone. Poeciliid Research, 2 (1): 1-8.

$\mathrm{Ng}$, C. (2016). The ornamental freshwater fish trade in Malaysia: The collection, breeding and marketing of ornamental fishes is a sizable industry. Ultra Agriculture Science Journal, 2 (4): 7-18.

Nelson, J. S., Grande, T. C. and Wilson, M. V. H. (2016). Fishes of the World. Fifth Edition. John Wiley and Sons, Inc., Hoboken, New Jersey. 707 pp.

Page, L. M. and Burr, B. M. (1991). A Field Guide to Freshwater Fishes: North America, North of Mexico. Houghton Mifflin Harcourt, Boston, USA. 432 pp.

Pankhurst, N. (1997). Temperature effects on the reproductive performance of fish. Global warming: implications for freshwater and marine fish, 61: 159.

Prodocimo, V. and Freire, C. A. (2001). Critical thermal maxima and minima of the platyfish Xiphophorus maculatus Günther (Poecillidae, Cyprinodontiformes) - a tropical species of ornamental freshwater fish. Revista Brasileira de Zoologia, 18 (1): 97-106. http://dx.doi.org/10.1590/S0101-81752001000500007

Shafiee, M., Yahyavi, M. and Yousefi, A. R. (2013). Determination of the breeding indices in different sex ratio of Poecilia reticulata. New Technologies in Aquaculture Development (Journal of Fisheries), 6 (4): 73-80. [in Persian]

Zanuy, S., Carrillo, M., Felip, A., Rodríguez, L., Blázquez, M., Ramos, J. and Piferrer, F. (2001). Genetic, hormonal and environmental approaches for the control of reproduction in the European sea bass (Dicentrarchus labrax L.). Aquaculture, 202 (3-4): 187-203. https://doi.org/10.1016/S0044-8486(01)00771-2 